\title{
Correction of Post-Traumatic Enophthalmos and Temporal Depression Using Rib Cartilage and Fat
}

\author{
Yeong Joon Kim, Seo Bin Kim, Joo Yeon Kim, and Jae Hwan Kwon \\ Department of Otolaryngology-Head and Neck Surgery, Kosin University College of Medicine, Busan, Korea \\ 안면부 외상 후 발생한 안구함몰 및 안면부 비대칭에서 늑연골과 지방을 이용한 교정술 \\ 김영준 · 김서빈 · 김주연 · 권재환 \\ 고신대학교 의과대학 이비인후과학교실
}

\author{
Received July 5, 2015 \\ Revised September 1,2015 \\ Accepted September 2, 2015 \\ Address for correspondence \\ Jae Hwan Kwon, MD, PhD \\ Department of Otolaryngology- \\ Head and Neck Surgery, \\ Kosin University \\ College of Medicine, \\ 262 Gamcheon-ro, Seo-gu, \\ Busan 49267, Korea \\ Tel +82-51-990-6247 \\ Fax +82-51-245-8539 \\ E-mail entkwon@hanmail.net
}

Posttraumatic enophthalmos is one of the common complications of facial bone fracture, leading to serious functional and esthetic sequele. However, the correction of this complication is a challenging procedure. A 62-year old patient was injured in a traffic accident, resulting in enophthalmos of the right orbit, which had been uncorrected by a previous correction surgery. The patient showed prominent enophthalmos, ptosis of right orbit, and temporal area depression without complaining diplopia. Under general anesthesia, the correction of enophthalmos of right orbit was done using diced coastal cartilage and an absorbable mesh plate. The depressed right temporal and the frontal area were reinforced using harvested abdominal fat. Three months after the surgery, additional fat injection was introduced to supplement under local anesthesia. Currently, 12 months after the surgery, the patient is in stable state without any complications.

Korean J Otorhinolaryngol-Head Neck Surg 2016;59(4):323-6
서 론

외상 후 발생한 오래된 안구함몰은 안면 골절의 합병증으 로 흔히 생기는 질환으로, 심한 기능적 및 심미적 장애를 유 발한다. 수술적 치료는 광대뼈 절골술 및 정위술(reduction), 보형물을 이용한 안와벽의 보강술 등이 있다. 최근 진단 및 수술기법의 발전으로 치료 결과의 개선이 있었음에도 불구하 고 아직 완전한 교정의 달성은 용이하지 않다. ${ }^{1)}$

저자들은 안면부의 외상 후 발생한 안구함몰과 안면부 비 대칭이 1 차 수술 시 불완전하게 교정된 환자를 늑연골과 지 방을 이용하여 성공적으로 교정하고 양호한 결과를 얻어 문 헌고찰과 함께 외상성 안구함몰 시의 치료에 대하여 논의하 고자 한다.

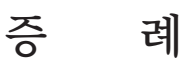

62세 여성이 내원 1년 전 교통사고 후 발생한 우측 안구 함몰을 주소로 본원에 내원하였다. 환자는 수상 당시 우측 삼각골절(tripod fracture), 상악골 골절, 우측 안와골절 및 전두골 골절이 발생하였으나 두개내 출혈로 인하여 수상 직 후에 안면부 외상에 대한 교정수술을 받지 못하였다. 수상 후 10 개월째 타 병원에서 교정적 절골술 및 우측 협골궁, 우 측 관전두골봉합, 양측 상악의 금속 플레이트 고정을 통한 안구함몰 교정술을 시행받았으나 수술 후 우측 안와의 함몰 및 안검 하수, 우측 측두부의 함몰을 지속적으로 호소하여 추가적 교정을 위하여 본원에 내원하였다. 안과검사상 양측 시력 우안 0.3 , 좌안 1.0 이며, 헤르텔 안구돌출검사(Hertel exophthalmometry)상 우측 안구는 좌측에 비해 $6 \mathrm{~mm}$ 함몰 되었고 복시는 호소하지 않았다(Fig. 1A). 
술 전 촬영한 안면부 CT상 이전 두개내 출혈 수술 시 고정 한 우측 전두골과 협골 간의 티타늄 판이 관찰이 되며 축면 $\mathrm{CT}$ 에서 우측 안구는 좌측 안구에 비해 현저히 함몰된 소견 이 관찰되었다. 관상면 $\mathrm{CT}$ 에서 우측 측두부의 형태 비정형 및 부피 결손, 우측 안와 하외벽의 결손이 관찰되었다(Fig. $1 \mathrm{~B}$ and $\mathrm{C})$.
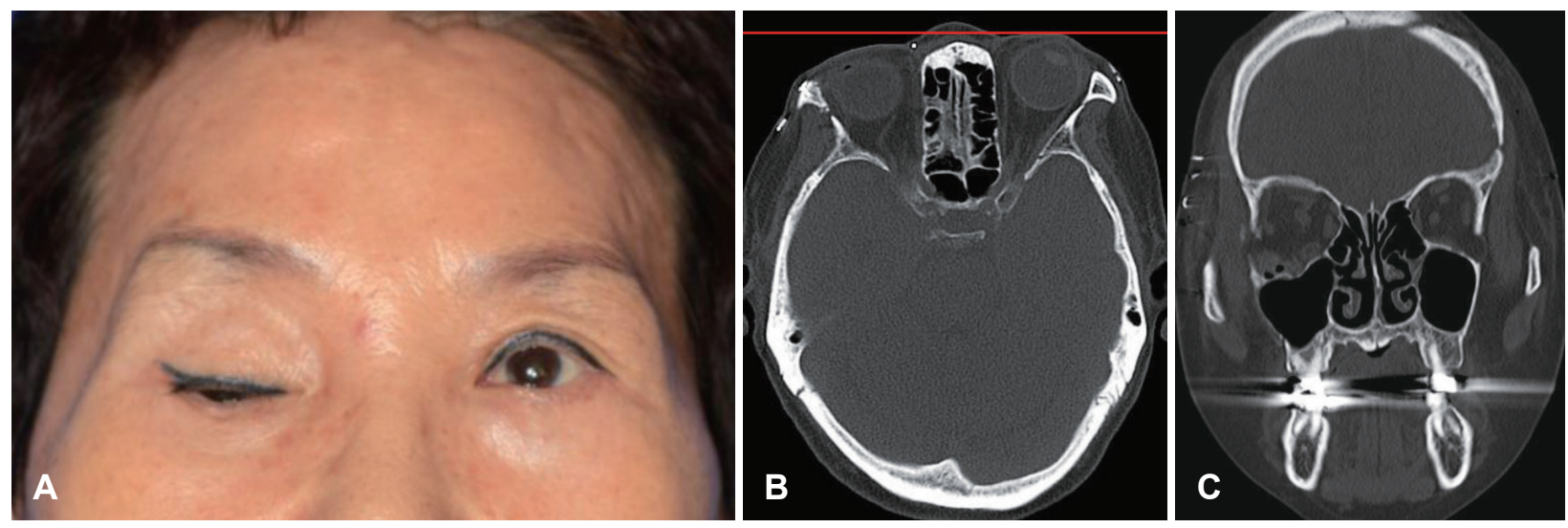

Fig. 1. Preoperative findings. The patient showed prominent enophthalmos and ptosis of right orbit, and temporal area depression (A). CT scan showed the right orbit depressed comparative to the left orbit (B). Red line is drawn to show the degree of orbit depression. In the coronal CT scan, inferolateral defect of right orbit is seen (C).
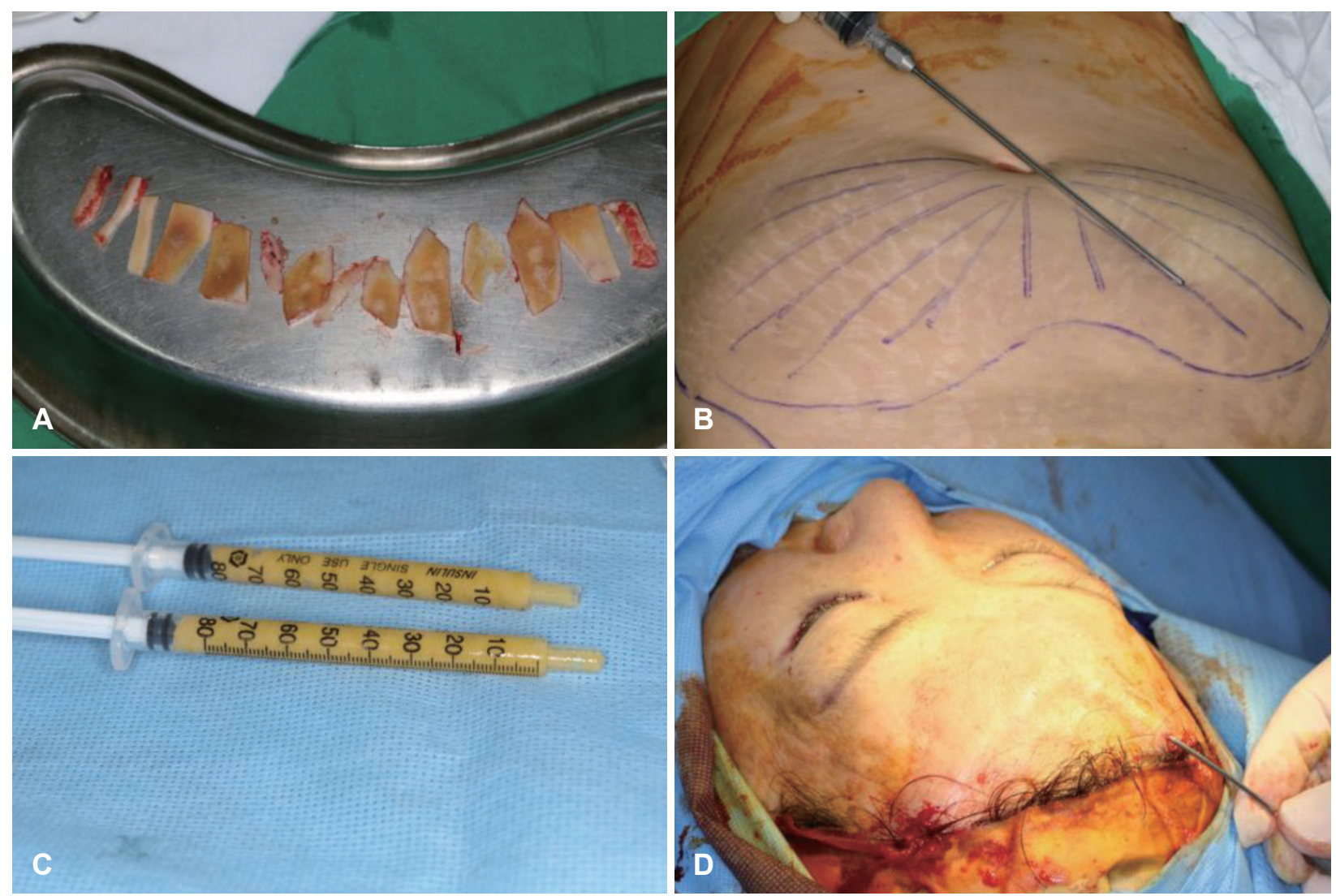

Fig. 2. Operative procedures. Diced cartilage harvested from the coastal cartilage of right 6 th rib $(A)$ and mesh plate was used for right orbital wall reconstruction. Abdominal fat was harvested infraumbilically $(B)$ and centrifugated for 6 minutes under $3000 \mathrm{rpm}$ and divided into $1 \mathrm{~mL}$ syringes $(\mathrm{C})$. The fat injection was done at right temporal area and frontal area, approached by 3 incisions, midline, left, and right side on hairline (D). 

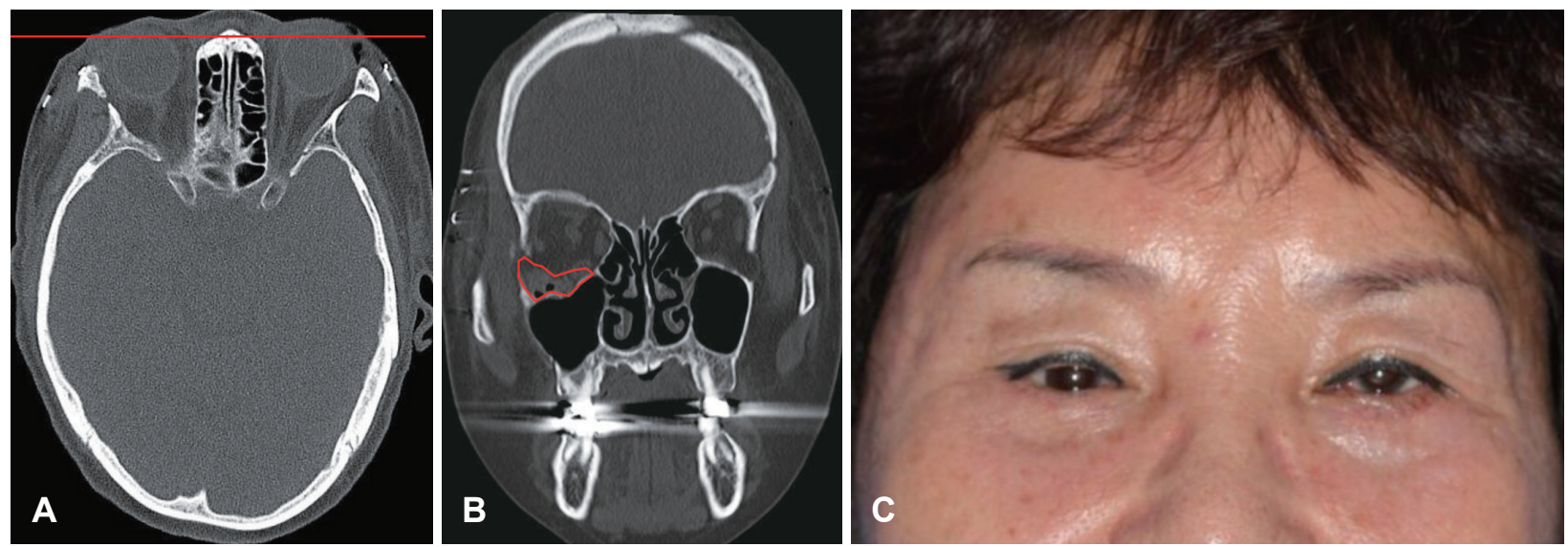

Fig. 3. Postoperative findings. Postoperative CT 1 day after the surgery shows that the depression of right orbit was corrected postoperatively (A). Inferolateral defect of right orbit was treated with rib cartilage and absorbable mesh plate placed at inferior orbital wall (B). The red circle shows the implanted diced rib cartilage. 12 months after the surgery, the enophthalmos, ptosis of right orbit, and the temporal area depression are much improved (C).

이식을 하였다. 하제부(infraumbilical area)의 절개를 통하 여 복부 피하지방에 접근하여 지방을 채취하였고, 채취된 피 하지방 및 용매의 혼합물을 $3000 \mathrm{rpm}$ 하에 6분 동안 원심분 리후 지질과 용매를 분리한 후, $1 \mathrm{cc}$ 주사기로 나누어 담아서 보관하였다. 우측 측두부 및 전두부에 찌름 절개(stab incision) 후 채취한 지방을 피하로 주입하여 보강하였다(Fig. $2 \mathrm{~B}, \mathrm{C}$, and D). 3개월 뒤 지방 흡수로 인한 우측 측두부 및 전두부의 함몰이 나타나, 이전 수술 시 사용 후에 냉동보관 한 지방을 활용하여 국소마취 하에 재주입술을 시행하였다.

술 후 촬영한 안면부 CT상 우측 안와 외하벽 골 결손 부 위에 늑연골이 충전되어 있는 것을 확인할 수 있었으며(Fig. $3 \mathrm{~A}$ and $\mathrm{B}), 1$ 차 수술 후 12 개월 경과한 현재 술 전에 비해서 안구함몰, 안검 하수 및 우측 측두부 함몰이 호전된 상태로 안정적으로 유지되고 있으며 특이소견 없이 경과관찰 중이 다(Fig. 3C).

\section{고 찰}

안구함몰은 안구의 골부 안와의 결손으로 인한 안구의 후 하방으로의 위치 이탈로 정의되며, ${ }^{2-5)}$ 골안와 확장에 의한 부 피의 증가에 비해 안구 연부 조직의 부피가 상대적으로 일정 하여 발생한다. ${ }^{2-4,6)}$ 외상으로 발생하는 안구함몰은 안구축의 뒤쪽 골절이나, 하벽골절과 내벽골절이 동반된 경우, 그리고 협골골절로 인한 안와외벽의 전위가 있을 경우에 잘 발생한 다. ${ }^{7)}$ 임상적으로 2 3 mm의 안구함몰부터 관찰 가능하며, 5 $\mathrm{mm}$ 이상의 경우 외형적으로 흥한 형태로 나타나며, 미용상 문제 외에도 안구의 하측 편위, 토안(lagophthalmos), 노출성 각막염, 복시 등이 동반되어 기능적인 문제도 일으키므로 적 절한 교정이 필요하다. ${ }^{3,6,8)}$
외상 후 안구함몰은 수술 전 진단의 지연, 수술 시 비정확 한 교정, 그리고 수상 직후의 생명을 위협하는 전신 상태의 문 제로 초기 수술을 시행하지 못한 경우에 주로 발생한다.

외상으로 인한 안구함몰의 경우 수술이 필요할 것으로 생 각되는 경우 절개가 용이하고 연부 부조직의 수축 등이 없어 수술이 용이한 수상 후 7일에서 14일 사이에 시행되어야 하며, 일차 교정술 이후에도 $10 \%$ 의 환자에서 잔존하는 안와 함몰 을 호소하고, 지연된 교정술 및 이차적 교정술은 일차 교정술 에 비해 성공률이 떨어지는 것으로 알려져 있다. ${ }^{3-5)}$

본 증례의 경우 환자는 수술 후 잔존하는 안구함몰을 호소 한 사례로서, 급성기에 전신 상태의 사유로 일차적 교정술을 시행하지 못하여 지연된 재건술을 시행하였으나, 잔존하는 안 와 이상 및 골부 결손부의 저명한 부피 결손이 발생한 경우이 다. 이 경우 다시 재골절을 시행하여 교정할 수도 있으나 본 증례의 경우 이미 상기 방법으로 수술을 시행하여 교정이 불 충분하였기에 넓어진 안와 용적을 늑연골 절편을 이용하여 충 전하는 방법으로 수술하였다. 최근 안와골절의 교정에 골부 결손의 절골술 등과 더불어 삽입물로 같이 교정하는 시도들 이 보고되는데, ${ }^{3,5}$ 본 증례의 경우 지연된 재건술로 낮은 성공 률을 감안해 일차 교정 시 삽입물 사용을 같이 고려하는 것 이 필요하였을 것으로 생각된다.

안구함몰을 교정하는 삽입물로는 뼈나 연골 등의 자가조직 과 실리콘, 하이드록시아파타이트, 다공성 폴리에틸렌, 티타 늄 등의 인공 삽입물이 있다.) 자가연골은 채취 및 조작이 쉽 고 감염에 강할 뿐만 아니라 비교적 공여부 결손이 적고 수여 부와 동시 수술이 가능하여 수술시간을 줄일 수 있는 장점이 있다.69) 늑연골 이식 시는 절편 연골 이식이 두꺼운 연골 블록 사용보다 흡수가 적고 유연성이 많아 굴곡에 따른 가공이 필 요 없으며 블록보다 이식편 사이에 빈공간이 적다는 장점을 
보인다. 흡수는 예측하기 어려우나 이식 후 흡수는 최소한으 로 나타나는 것으로 보고되었다. ${ }^{6,10}$ 골 자가이식편의 경우 손 상부위와 같은 조직이므로 감염저항력이 강하지만 골 채취를 위한 공여부의 수술이 필요하다. ${ }^{6)}$

인공 삽입물은 재료 채취를 위한 수술이 필요 없으며, 다루 기가 쉽고, 3 차원적 재건이 가능하며 짧은 수술시간 등의 장 점으로 널리 사용되지만 비싼 가격과 생체적합성에 문제가 있 다. 흡수성 메쉬는 숙주조직에 흡수가 되므로 장기 합병증을 유발하지 않고 부드러워 주변조직에 압박손상을 주지 않으나 감염에 약하고 흡수가 되면서 염증반응을 일으킬 수 있다는 단점이 있다. ${ }^{7}$ 년 후 지지력이 $50 \%$ 유지되며 약 18 36개월에 걸쳐 완전히 흡수된다. ${ }^{11)}$ 본 사례의 경우 자가조직과 인공 삽 입물 양측의 장점을 취하기 위하여 동시에 사용하였는데, 감 염에 강한 자가연골을 사용하되 부족분을 메쉬를 통하여 보 충하였다.

안구함몰은 시간이 지나면서 점차 악화된다는 보고들이 흔 히 있다. ${ }^{1)}$ 이는 수술로 인한 부종으로 인하여 불충분한 교정을 발견 못하거나, 안와 내 연부 조직의 재형성 및 성숙화 단계 시 조직의 형태 변화에서 기인한다. ${ }^{1)}$ 본 증례의 경우 수술 12 개월이 지난 시점까지 안정적인 결과를 보여주었으나, 잠재적 발생 가능성을 염두에 두고 지속적 관찰이 필요할 것으로 생 각된다.

지방 자가이식은 지방의 생체적합성, 채취 및 가공의 용이 함, 및 주입양의 조절의 용이성으로 인하여 성형 및 재건수술 에 널리 쓰이고 있으나, 주입용적의 유지의 결과가 예측이 어 려운 점이 단점이다. ${ }^{12}$ 괴사나 재흡수로 인하여 1 년 동안 지방 생존율이 $40 \%$ 에서 $70 \%$ 정도인 점을 고려하여 과교정을 하지 만, 드물게 과잉교정이 보고된 경우가 있음을 감안해야 한 다. ${ }^{12-15)}$ 재흡수를 감안하여 추후 추가 주입을 계획할 수 있으 며, 정해진 주입시기는 알려져 있지 않다.

지방의 채취 시 시술 후 남은 지방을 멸균 냉동보관하는 것 이 추후 지방의 추가 주입을 위해 필요하다. ${ }^{14}$ 지방 자가이식 은 안전한 술식으로 간주되지만, 감염, 출혈, 지방색전, 비대 칭, 육아종, 이물질 주입 등의 발생을 주의해야 한다. ${ }^{13,14)}$

지방의 공여부는 복부, 대퇴부, 둔부 등에서 채취하는데, 하 복부 및 내측 대퇴부가 타 부위에 비하여 생착에 유리하다는 보고가 있으나 관련이 없다는 보고도 있으며, 공여부는 부피 의 적절성 및 환자 개인 선호도 등을 고려하여 채취한다. ${ }^{12,13)}$ 채취 시 투메센트(tumescent) 용액을 이용하면 통증을 줄이 며 많은 양의 지방을 채취할 수 있으며 출혈 및 지방 색전증 예방에 도움을 준다. ${ }^{14)}$ 채취 시 음압이 적을수록, 직경이 큰 캐
뉼라를 쓸수록 지방세포의 손상을 줄일 수 있다. ${ }^{12-14)}$ 분리된 지방은 원심분리를 시행하여 혈액층 및 지방오일층으로부터 지방 조직을 분리하여 주입부위에 조금씩 여러 층에 나누어 주입하여 피부 표면이 불규칙해지는 것을 최소화한다. ${ }^{12-14}$

외상 후 안구함몰의 교정은 용이하지 않은 임상적 과제로, 특히 지연 교정 혹은 이차적 교정 시 많은 어려움을 야기한다. 이에 저자들은 심미적 요소를 포함하고 술후 잠재적 재발 가 능성을 염두에 두며 합병증의 발생을 최소화한 정교한 술전 계획을 수립하고 삼차원 영상학적 검사 및 네비게이션 등을 이용한 수술을 시행하는 것이 양호한 임상적 결과를 위하여 필요할 것으로 생각한다.

\section{REFERENCES}

1) Kim YH, Ha JH, Kim TG, Lee JH. Posttraumatic enophthalmos: injuries and outcomes. J Craniofac Surg 2012;23(4):1005-9.

2) Clauser L, Galiè M, Pagliaro F, Tieghi R. Posttraumatic enophthalmos: etiology, principles of reconstruction, and correction. J Craniofac Surg 2008;19(2):351-9.

3) Hazani R, Yaremchuk MJ. Correction of posttraumatic enophthalmos. Arch Plast Surg 2012;39(1):11-7.

4) Hamedani M, Pournaras JA, Goldblum D. Diagnosis and management of enophthalmos. Surv Ophthalmol 2007;52(5):457-73.

5) Metzler P, Ezaldein HH, Pfaff MJ, Parsaei Y, Steinbacher DM. Correction of severe enophthalmos by simultaneous fat grafting and anatomic orbital reconstruction. J Craniofac Surg 2014;25(5):1829-32.

6) Kwon MS, Kim JG, Bae KB, Kwon JH, Cho JH. Repair of late posttraumatic enophthalmos. Korean J Otolaryngol-Head Neck Surg 2007; 50(2):128-33.

7) We J, Jung T, Noh W, Kwon J. Reconstruction of bony orbit using endoscope and polyethylene with embedded titanium for a patient with postoperative enophthalmos. Korean J Otorhinolaryngol-Head Neck Surg 2009;52(11):928-31.

8) Rubin PA, Rumelt S. Functional indications for enophthalmos repair. Ophthal Plast Reconstr Surg 1999;15(4):284-92.

9) Lee J. Preplanned correction of enophthalmos using diced cartilage grafts. Br J Plast Surg 2000;53(1):17-23.

10) Sajjadian A, Rubinstein R, Naghshineh N. Current status of grafts and implants in rhinoplasty: part I. Autologous grafts. Plast Reconstr Surg 2010;125(2):40e-9e.

11) Han JU, Im JS, Suk SH, Kim JY, Kim SW, Park TJ, et al. The surgical results of isolated orbital blowout fractures using bioresorbable poly L-/DL-Lactide 70/30 implant. Korean J Otorhinolaryngol-Head Neck Surg 2014;57(11):759-65.

12) Gabriel A, Champaneria MC, Maxwell GP. Fat grafting and breast reconstruction: tips for ensuring predictability. Gland Surg 2015;4(3): 232-43.

13) Gutowski KA; ASPS Fat Graft Task Force. Current applications and safety of autologous fat grafts: a report of the ASPS fat graft task force. Plast Reconstr Surg 2009;124(1):272-80.

14) Kang IG. Fat implantation. In: Kang IG, Kang JG, Kim SH, Kim IS, Kim JH, Kim CH, et al., editors. Facial plastic and reconstructive surgery. 1st ed. Seoul: Koonja;2014. p.545-51.

15) Zocchi ML, Zuliani F. Bicompartmental breast lipostructuring. Aesthetic Plast Surg 2008;32(2):313-28. 